\title{
Contaminação por mercúrio em sushi/sashimi comercializados em restaurantes do município de Niterói-RJ - Brasil
}

\author{
Mercury contamination in sushi/sashimi comercialized in the \\ Niterói's restaurants - Brazil
}

\author{
Márcio Henrique de Oliveira Garcia, ${ }^{\star}$ Eliane Teixeira Mársico, ${ }^{\star *}$ Sérgio Carmona de São Clemente, ${ }^{* *}$ \\ José Maria dos Santos Filho***
}

\begin{abstract}
Resumo
O presente trabalho determinou a concentração de mercúrio em sushi/sashimi comercializado nos restaurantes do município de Niterói-RJ. Utilizou-se um total de 47 amostras, sendo 26 de atum e 21 de salmão. Para a determinação dos teores de mercúrio foi utilizada a técnica de espectrofotometria de absorção atômica por arraste de "vapor a frio". Os resultados encontrados demonstraram que os teores de mercúrio para as amostras de sushi/sashimi confeccionadas à base de atum, variaram entre 0,034 e 0,598 mg/g e no salmão, entre 0,003 e 0,021 mg/g. É importante destacar que duas amostras de atum ultrapassaram o limite tolerado pela legislação brasileira para peixes, estabelecido em 0,5 ppm., donde conclui-se que, cada vez mais, aumenta a importância na monitorização dos teores de mercúrio em pescado, para que sejam preservados a saúde e o bem-estar da população.
\end{abstract}

Palavras-chave: mercúrio; sushi; sashimi; contaminação.

\begin{abstract}
This communication reports concentrations of total mercury in samples of sushi and sashimi comercialized in Niterói's restaurants, Rio de Janeiro. 47 samples were analysed, being 26 of tuna and 21 of salmon. The analytical methodology was performed by using a cold vapour atomic absorption spectrofotometry in a mercury analyzer system (bacharach Coleman model MAS- 50B). The values obtained for tuna's samples ranged $0,034 \mathrm{mg} / \mathrm{g}$ to $0,598 \mathrm{mg} / \mathrm{g}$ and for salmo fish 0,003 to $0,021 \mathrm{mg} / \mathrm{g}$. It's important to observe that two samples of tuna fish exceed the limit allowed for Brazilian legislation $(0,5 \mathrm{mg} / \mathrm{g})$. We can concluded that it's important to monitorize the levels of mercury contamination in fish to preserve public health.
\end{abstract}

Keywords: mercury; sushi; sashimi; contamination.

\section{Introdução}

Os alimentos são a principal fonte de mercúrio para pessoas que não possuem exposições ocupacionais e o pescado e seus derivados são os que fornecem maior quantidade de metil-mercúrio (forma mais tóxica do metal) na alimentação.

A contaminação do pescado pelo metal mercúrio pode trazer graves conseqüências para a saúde pública, pois se trata de um metal pesado comprovadamente bioacumulativo cujos efeitos negativos e riscos para a saúde humana já foram extensamente comprovados.

Para a economia mundial, as conseqüências são bem sérias. Atualmente, as indústrias de pescado já têm implantado o Sistema APPCC - Análise de Perigos e Pontos Críticos de Controle, programa baseado na prevenção e considerado o melhor plano para garantir a segurança e qualidade dos produtos de origem animal. Muitas indústrias e entrepostos de pesca já procuram monitorar o teor de mercúrio em peixes predadores e carnívoros, que possuem potencial de assimilação maior que outras espécies, em função da bioacumulação e pelo fato de estarem no topo da cadeia alimentar.

Tollefson e Cordle (1986) afirmam que a ingestão de peixes com grande quantidade de metilmercúrio é perigosa e que existem algumas evidências que sugerem que este composto pode causar disfunções neurológicos leves quando ingerido, mesmo em níveis moderados, principalmente no período pré-natal e na infância, que são os estágios da vida mais vulneráveis devido à sensibilidade do sistema nervoso durante o seu desenvolvimento

No Brasil, adota-se o limite máximo de 0,5 ppm. de mercúrio total para peixes, e de 1,0ppm para peixes predadores, limite esse estabelecido pela Instrução Normativa no 42 - MAA (Brasil, 1999).

\footnotetext{
* Médico Veterinário autônomo

** Departamento de Tecnologia de Alimentos - Faculdade de Veterinária- Universidade Federal Fluminense. Rua Vital Brazil Filho, 64 - CEP: 24230-340- Vital Brazil- Niterói-RJ.

*** Faculdade de Veterinária- Universidade Estadual do Ceará
} 
A técnica mais utilizada em provas de rotina é a espectrofotometria de absorção atômica com arraste de "vapor frio" (Hendzel, Jamielson, 1976 ; Torre, Soldevilla, 1985 ; Vargas, Romero, 1992 ; Diaz et al., 1994).

Deitz et al. (1973) descrevem um método de espectrofotometria de absorção atômica por arraste de "vapor frio", simples e rápido, podendo ser utilizado para vários tipos de amostras biológicas. Os autores modificaram técnicas descritas por outros pesquisadores, utilizando um catalisador de reação (pentóxido de vanádio). Para digestão utilizaram ácido nítrico e sulfúrico, sob aquecimento a $140^{\circ} \mathrm{C}$, para obter a liberação do mercúrio, do dimetilmercúrio. A quantidade de amostra utilizada deve estar totalmente coberta com ácido nítrico antes de ser levada a aquecimento para minimizar as perdas de mercúrio, e a redução de mercúrio a sua forma volátil é feita com a adição de sulfato de estanho.

Objetivou-se, nesta pesquisa, determinar o teor de mercúrio em amostras de sushi e sashimi elaborados com atum e salmão, o que é justificado pela oferta cada dia maior de restaurantes especializados neste tipo de produto, e pela sua crescente aceitação, de cunho social, étnico e cultural.

\section{Material e método}

As amostras de sushi e sashimi confeccionadas à base de atum e salmão foram coletadas em restaurantes, identificadas, acondicionadas em sacos plásticos e encaminhadas ao Laboratório de Controle Físico-Químico de Produtos de Origem Animal da Faculdade de Veterinária da Universidade Federal Fluminense, onde foram estocadas em freezer comercial comum a $-25^{\circ} \mathrm{C}$. Antes das análises, as amostras sofrem descongelamento lento em geladeira comercial comum a $5^{\circ} \mathrm{C}$. Posteriormente, foram cominuidas, homogeneizadas e pesadas em alíquotas de $4 \mathrm{~g}$. Analisaram-se 47 amostras, sendo 26 de atum e 21 de salmão.

Após sofrer descongelamento lento em geladeira comum a $5^{\circ} \mathrm{C}$, as amostras foram cominuídas e pesadas em alíquotas de $4 \mathrm{~g}$ em duplicata.

Após cada análise, lavava-se e rinsava-se com água destilada toda a vidraria utilizada: Semanalmente, deixava-se de molho em solução de ácido nítrico a $2 \%$ por 48 horas, e antes de serem reutilizadas rinsava-se com água destilada e colocava-se em estufa a $110^{\circ} \mathrm{C}$, por 10 minutos, para secagem.

Para cada bateria de análise preparou-se uma solução de cloreto estanoso a $10 \%$, adicionando-se $10 \mathrm{~g}$ de cloreto de estanho a $20 \mathrm{ml}$ de ácido clorídrico concentrado, com ligeiro aquecimento a $90^{\circ} \mathrm{C}$ para facilitar a dissolução. Em seguida, diluiu-se a $100 \mathrm{~mL}$ com água destilada.

O método de determinação de mercúrio baseou-se na técnica descrita por Deitz, Sell e Bristol (1973), com algumas modificações, e o equipamento (Bacharach Coleman MAS - 50 B) utiliza a técnica de espectrofotometria de absorção atômica por arraste de vapor a frio, fornecendo o resultando em microgramas de mercúrio por grama da amostra.
As alíquotas foram cominuídas com auxílio de bisturi e pinça em uma placa de petri e pesadas em balança analítica, alíquotas de $4 \mathrm{~g}$, em duplicata. Adicionaram-se a cada tubo de hidrólise $0,040 \mathrm{~g}$ de pentóxido de vanádio e $15 \mathrm{~mL}$ de ácido nitríco concentrado, que foram colocados em bloco digestor a $140^{\circ} \mathrm{C}$, em capela, por um período de 20 minutos, após os quais foram retirados do bloco e resfriados em temperatura ambiente no interior da capela por aproximadamente cinco minutos. Após este procedimento, foram adicionados $30 \mathrm{~mL}$ de ácido sulfúrico concentrado, e os tubos foram reaquecidos a $140^{\circ} \mathrm{C}$ por mais 25 minutos e resfriados em temperatura ambiente por cinco minutos no interior da capela. O ácido sulfúrico concentrado, além de digestor da matéria orgânica, realiza a conversão do mercúrio orgânico em mercúrio inorgânico. Posteriormente foram adicionados aos tubos de hidrólise $10 \mathrm{~mL}$ de água destilada, sendo os tubos reaquecidos a $140^{\circ} \mathrm{C}$, por 15 minutos e resfriados por mais cinco minutos. Uma última fase de aquecimento foi realizada completando o volume dos tubos a $100 \mathrm{~mL}$ e aquecendo-os a $100^{\circ} \mathrm{C}$ por 20 minutos. Em seguida, os tubos foram resfriados em temperatura ambiente e em água corrente, e posteriormente colocados em banho de gelo, facilitando a leitura das amostras.

É importante destacar que durante todas as fases do processo os tubos devem ser freqüentemente agitados para favorecer a eliminação dos vapores de óxido de nitrogênio, que causam interferência na leitura por absorção atômica. Para segurança na metodologia, a cada frasco de reagente aberto foram feitas análises de "brancos", para eliminar dos resultados finais os traços de contaminação por mercúrio dos reagentes.

A amostra mineralizada de cada tubo foi transferida para o frasco próprio do aparelho. Foram utilizados $10 \mathrm{~mL}$ de cloreto de estanho, que funciona como solução redutora, causando uma reação de conversão de todo o mercúrio presente em mercúrio metálico e proporcionando a liberação do vapor deste mercúrio, juntamente com aeração da bomba do aparelho, carreando, desta forma, todo o vapor do metal para a célula de absorção. O mercúrio na forma atômica abśorve radiação de comprimento de onda na faixa de $253,7 \mathrm{~nm}$, emitida pela fonte de luz.

Antes do início do experimento comprovaram-se as condições do aparelho utilizando uma solução de concentração conhecida de mercúrio.

O tratamento estatístico dos resultados foi feito através da análise de variância - ANOVA, utilizando-se o programa Microsoft Excel versão 7.0, da Microsoft.

\section{Resultados}

Os resultados obtidos nas amostras estudadas podem ser observados na Tabela 1, onde destacam-se os níveis de mercúrio em duas amostras de atum (22 e 23), que atingiram valores acima do limite tolerado pela legislação brasileira, sem, contudo, exceder o limite previsto para peixes predadores. 
Tabela 1: Teor de mercúrio $(\mu \mathbf{g} / \mathbf{g})$ das amostras de atum e salmão

\begin{tabular}{ccc}
\hline \multicolumn{3}{c}{ Teor de Mercúrio $(\mu \mathbf{g} / \mathbf{g})$} \\
\hline Amostras & Atum & Salmão \\
\hline 1 & 0,030 & 0,026 \\
2 & 0,039 & 0,021 \\
3 & 0,034 & 0,025 \\
4 & 0,052 & 0,025 \\
5 & 0,193 & 0,023 \\
6 & 0,236 & 0,018 \\
7 & 0,074 & 0,008 \\
8 & 0,154 & 0,003 \\
9 & 0,139 & 0,050 \\
10 & 0,191 & 0,048 \\
11 & 0,053 & 0,117 \\
12 & 0,069 & 0,211 \\
13 & 0,129 & 0,113 \\
14 & 0,364 & 0,031 \\
15 & 0,307 & 0,009 \\
16 & 0,065 & 0,003 \\
17 & 0,191 & 0,005 \\
18 & 0,498 & 0,009 \\
19 & 0,216 & 0,029 \\
20 & 0,235 & 0,031 \\
21 & 0,399 & 0,026 \\
22 & $\mathbf{0 , 5 9 8}$ & - \\
23 & $\mathbf{0 , 5 1 0}$ & - \\
24 & 0,213 & - \\
25 & 0,236 & - \\
26 & 0,460 & - \\
\hline Média & $\mathbf{0 , 2 2 0} \pm \mathbf{0 , 1 6}$ & $\mathbf{0 , 0 4 0 \pm 0 , 0}$ \\
\hline \hline
\end{tabular}

Os valores mínimos, máximos, médios e o desvio-padrão para cada amostra podem ser visualizados na Tabela 2.

Tabela 2: Valores mínimos, máximos, médios e o desvio-padrão das amostras estudadas de atum e salmão.

\begin{tabular}{cccc}
\hline \hline Amostras & Valor Mínimo & Valor Máximo & Média \\
\hline Atum & 0,034 & 0,598 & $0,22 \pm 0,16$ \\
Salmão & 0,003 & 0,211 & $0,04 \pm 0,05$ \\
\hline
\end{tabular}

Os resultados obtidos foram submetidos à análise de variância - ANOVA, que, calculando o valor $F$, evidenciou que os valores médios estudados para as amostras de atum e salmão são estatisticamente diferentes.

\section{Referências bibliográficas}

BECKET, J.S., FREEMAN, H.C. Mercury in Swordfish and other Pelagic Species from the western Atlantic Ocean. In: Proccedings of the International Billfish Symposium. Kailua- kona, Hawai, p. 154159, 1972.

\section{Discussão}

O fato de as amostras de atum apresentarem teores mais elevados de mercúrio é explicado pelos seus hábitos alimentares e sua posição na cadeia trófica, pois o mercúrio sofre biomagnificação e bioacumulação no ambiente marinho, ou seja, ao ir passando de um elo a outro da cadeia alimentar, as concentrações de mercúrio sofrem um incremento, dando lugar a maiores concentrações no final da cadeia trófica. Francesconi e Lenanton (1992) pesquisaram peixes provenientes de uma baía semifechada no Sul da Austrália, que recebia despejos de uma indústria química, cujos resultados demonstraram baixos níveis de contaminação mercurial no sedimento e níveis altíssimos nos peixes. Vários autores relatam que, em peixes predadores, que se encontram na parte superior da cadeia alimentar, os teores de mercúrio são maiores do que em peixes herbívoros e onívoros (Cattaneo et al., 1988 ; Beckett, Freeman, 1972 ; Comissão do Codex Alimentarius, 1972 ; Wren et al., 1991).

Vários autores relatam níveis altos de mercúrio em tunídeos. Tollefson e Cordle (1986) evidenciaram valores entre 0,156 e $0,324 \mu \mathrm{g} / \mathrm{g}$; Simpson et al. (1974) constataram teor médio de $0,25 \mu \mathrm{g} / \mathrm{g}$ e $4 \%$ das amostras estudadas com valor superior a $0,5 \mu \mathrm{g} / \mathrm{g}$, fato também constatado neste estudo. Valores médios mais elevados foram observados por Mariño e Martín (1976), de 0,370 $\mu \mathrm{g} / \mathrm{g}$, e por Souza e Goyanes (1992), também de $0,370 \mu \mathrm{g} / \mathrm{g}$. Valor médio semelhante ao observado neste estudo para as amostras de atum foi constatado por Romano (1999), que, estudando exemplares de bonito de barriga listrada (Katsuomus pelamis), encontrou valor médio de $0,208 \mu \mathrm{g} / \mathrm{g}$.

Chicourel et al. (1995) advertem que existe a possibilidade de não termos mais casos de intoxicação por mercúrio na população brasileira, devido ao baixo consumo de peixe da população. Entretanto, isso não elimina o risco tóxico, muito menos justifica a falta de atenção para o problema, principalmente em algumas regiões consideradas de risco, onde 0 consumo de pescado é muito alto, ou regiões próximas a garimpos.

\section{Conclusão}

- A posição ocupada pelo peixe na cadeia trófica e seus hábitos alimentares tem completa influência no conteúdo do metal presente no tecido muscular, fato este comprovado nas amostras de atum.

- Apesar da maior parte dos valores encontrados se encontrar abaixo do limite estabelecido pela legislação vigente, como se trata de um metal altamente tóxico, de efeito residual, que apresenta altas taxas de absorção e taxas extremamente baixas de excreção, é um fator preocupante, visto que outras fontes de exposição são referidas na literatura.

BRASIL. Ministério da Agricultura e do Abastecimento - Secretaria de Defesa Agropecuária. Instrução Normativa no 42, de 20 de dezembro de 1999.

BRASIL. Ministério da Agricultura. Contaminação do Pescado por Mercúrio. Circular № 182/BR. Comitê do Codex Sobre Pescado e Derivados. Brasília, DF, 1972, $13 p$. 
CATTANEO, P., BALZARETTI, C., CATONI, C. Mercúrio in specie Ittiche del Basso Mincio. Archivio Veterinário Italiano, Milano, v. 39, n. 5/6, p. 119-202, 1988.

CHICOUREL, E.L., TENUTA FILHO, A., SAKUMA, A.M., ZENEBON, O., AMORIM, A.R. Mercúrio em pescado comercializado em São Paulo -SP, Brasil. Ciência e Tecnologia Alimentar, São Paulo, v. 15, n. 2, p. 144-149, 1995.

DEITZ, F.D., SELL, J.L., BRISTOL, D. Metals and Other Elements Rapid, Sensitive Method for Determination of Mercury in a Variety of Biological Samples. J. Assoc. Off. Anal. Chem, v. 56, n.2, p. 378382, 1973.

DIAZ, C., PADRÓN, A.G., FRÍAS, I., HARDISSON, A., LOZANO, G. Concentration of Mercury in Fresh and Salted Marine Fish From the Canary Islands. Joumal of Food Protection, v. 57, n.3, p- 246-248, 1994.

FRANCESCONI, K.A.; LENANTON, R.C.J. Mercury Concentration in a Semi-enclosed Marine Embayment: Organic and Inorganic Mercury Contents of Biota and Factors Influencing Levels in Fish. Marine Environmental Research, v. 33, p. 189-212, 1992.

HENDZEL, M. R., JAMIELSON, D.M. Determination of Mercury in Fish. Analytical Chemistry, Winnipeg, v. 48, n.6, p. 926-928, 1978.

MARIÑO, M., MARTÍN, M. Contenido de Mercurio en Distintas Especies de Moluscos y Pescados. Anales de Bromatología, v. 28, n. 2, p. 155-178, 1976.
ROMANO, V.P., SANTOS, N.N., SÃO CLEMENTE, S.C., OLIVEIRA, G.A., ZAMBORLINI, L.C. Níveis de Mercúrio em Cinco Espécies de Peixes do Litoral DE Cabo Frio, Rio de Janeiro, RJ. Higiene Alimentar, São Paulo, v. 13, n. 60, p. 49-54, mar.1999.

SIMPSON, R.E., HORWITZ, W., ROY, C.A. Survey of Mercury Levels in Fish and Other Foods. Pesticides Monitoring Journal, v. 7, n. 314, p. 127-138, 1974.

SOUZA, J.V.B., GOYANES, A. L. Contenido de Mercurio en Productos de la Pesca por Espectrofotometría de Absorción Atómica en Vapor Frio. Anales de Bromatologia, v. 44, n.1, p. 45-57, 1992.

TOLLEFSON, L., CORDEL, F. Methylmercury in Fish: a Review of Residue Levels, Fish Consumption and Regulatory Action in the United States. Environmental Health Perspectives, v. 68, p. 203-208, 1986.

TORRE, A.H., SOLDEVILLA, G.L. Mercurio en Especies Marinas. Alimentaria, v. 22, n. 163, p. 59-65, jun. 1985.

VARGAS, M.C., ROMERO, R.A. Mercury Determination by Cold Vapour Atomic Absorption Spectrometry in Several Biological Indicators from Lake Maracaibo, Venezuela. Analyst., v.117, p. 645-647, 1992.

WREN, C.D., SCHEIDER, W.A., WALES, D.L., MUNCASTER, B.W., GRAY, I.M. Relation Between Mercury Concentration in Welleye (Stizostedion vitreum vitreum) and Northern Pike (Esox lucius) in Ontario Lakes and Influence of Environmental Factors. Can.J. Fish. Aquatic. Sci., Toronto, v. 48, p. 132-139, 1991.

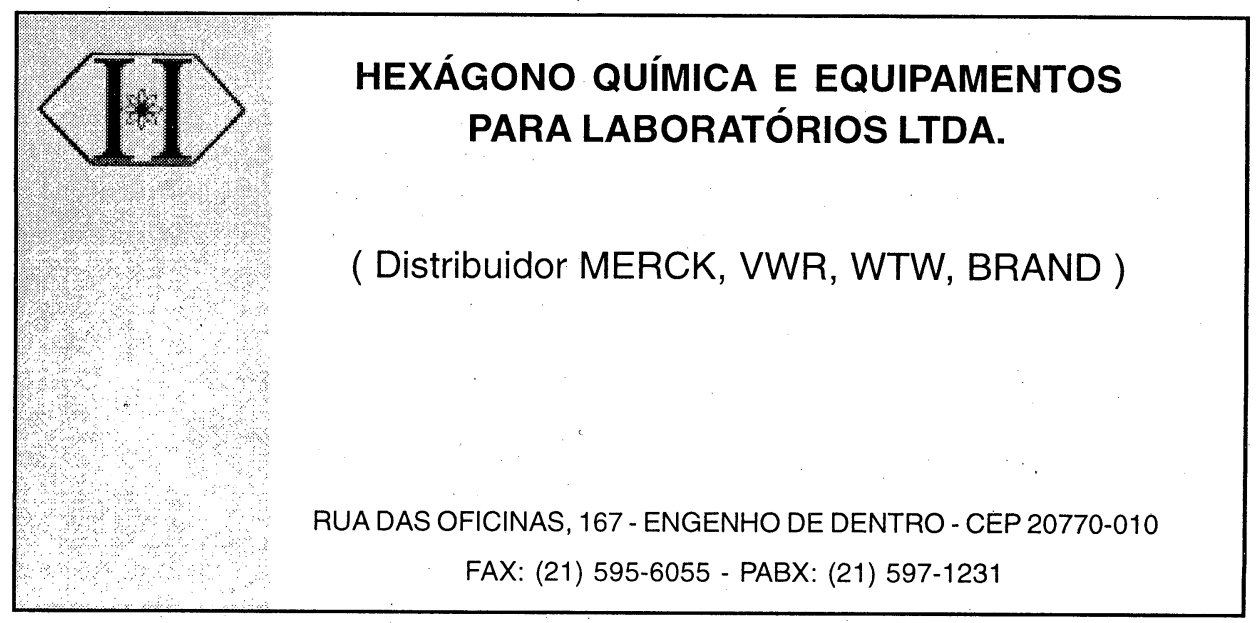

